\title{
Tortícolis en la edad pediátrica: Revisión pictográfica
}

\begin{abstract}
Dres. Manuela Pérez $M^{(1)}$, Ximena Ortega $F^{(1)}$, Susana Lillo(2), Karla Moenne $B^{(1)}$, Juan Antonio Escaffi ${ }^{(1)}$, Carolina
\end{abstract} Pérez $\mathbf{S}^{(1)}$.

Diagnóstico por Imágenes, Radiología Infantil. Clínica Las Condes. Santiago, Chile.

Departamento de Fisiatría. Clínica Las Condes. Santiago, Chile.

\section{Torticollis in children: A pictographic review}

Abstract. Torticollis describes the clinical finding of an abnormal positioning of the head related with the body axis, with cervical rotation and contralateral tilt of the head, which is usually secondary to an involuntary contraction of the cervical musculature been sternocleidomastoideus muscle (ECM) the most important component. As a clinical sign, differential diagnosis is very broad, and may be secondary to multiple causes. Pediatric population has a particular spectrum of diseases which differs from adults. The aim of this pictorial review is to evaluate some torticollis causes in the pediatric setting recording main imaging findings and their contribution to the clinical diagnosis.

Keywords: Children, Imaging, Torticollis.

Resumen. La tortícolis describe el hallazgo clínico de una posición anómala de la cabeza respecto del eje corporal, con rotación cervical e inclinación contralateral de la cabeza, que habitualmente es secundaria a una contracción involuntaria de la musculatura cervical con compromiso predominante del músculo esternocleidomastoídeo (ECM). Como signo clínico su diagnóstico diferencial es muy amplio, pudiendo ser secundario a múltiples causas. En la edad pediátrica el espectro es particular y difiere de la forma reconocida en adultos. El objetivo de esta revisión pictográfica es evaluar algunas de las causas de torticolis en la edad pediátrica y analizar los principales hallazgos imaginológicos y su aporte al diagnóstico clínico. Palabras clave: Imágenes, Niños, Torticolis.

Pérez M, et al. Tortícolis en la edad pediátrica: Revisión pictográfica. Rev Radiol 2013; 19(3): 125-133.

Correspondencia: Dra. Manuela Pérez M. / maneperez@yahoo.com

Trabajo recibido el 11 de junio de 2013, aceptado para publicación 30 de septiembre de 2013.

\section{Material y métodos}

Revisión retrospectiva de pacientes menores de 15 años que presentaron tortícolis entre sus síntomas de ingreso, entre junio del 2007 y julio del 2011, evaluados con radiografía simple, ultrasonido, tomografía computada (TC) o resonancia magnética (RM).

\section{Resultados}

Las causas que originan la tortícolis pueden situarse en las estructuras óseas de la base del cráneo y columna cervical, en las partes blandas del cuello y en el SNC. En el intervalo de tiempo explorado, se presentaron pacientes con tortícolis secundaria a patologías tanto de partes blandas como de estructuras óseas, resumidas en la Tabla I. A continuación se presentan imágenes y comentarios de casos elegidos de cada patología, destacando sus características imaginológicas en las diferentes modalidades de estudio.

\section{A) Partes blandas del cuello Fibromatosis Colli}

La tortícolis muscular congénita (TMC) o Fibromatosis Colli es una condición patológica caracterizada por cambios morfológicos y funcionales de los musculos Esternocleidomastoídeos (ECM), cuya etiopatogenia aún no ha sido precisada. Se manifiesta clínicamente alrededor de la tercera semana de vida como una masa cervical, que puede ser sensible, o por inclinación de la cabeza hacia el lado afectado. Es más frecuente en asociación con parto traumático, en relación al uso de fórceps, en presentación podálica y en primíparas. Su manejo se basa fundamentalmente en la kinesioterapia, y su evolución clínica es generalmente autolimitada, pero puede dejar secuelas permanentes si no se trata.

La ecografía resulta de gran utilidad en el diagnóstico de la tortícolis muscular congénita. Los hallazgos consisten en un aumento de volumen relativamente 
homogéneo del músculo comprometido, con aspecto de masa sólida bien delimitada, que generalmente compromete los tercios superior o medio del músculo. Su ecogenicidad suele ser ligeramente mayor o menor que el músculo sano adyacente y puede presentar aumento de la vascularización durante la exploración Doppler color (Figura 1).
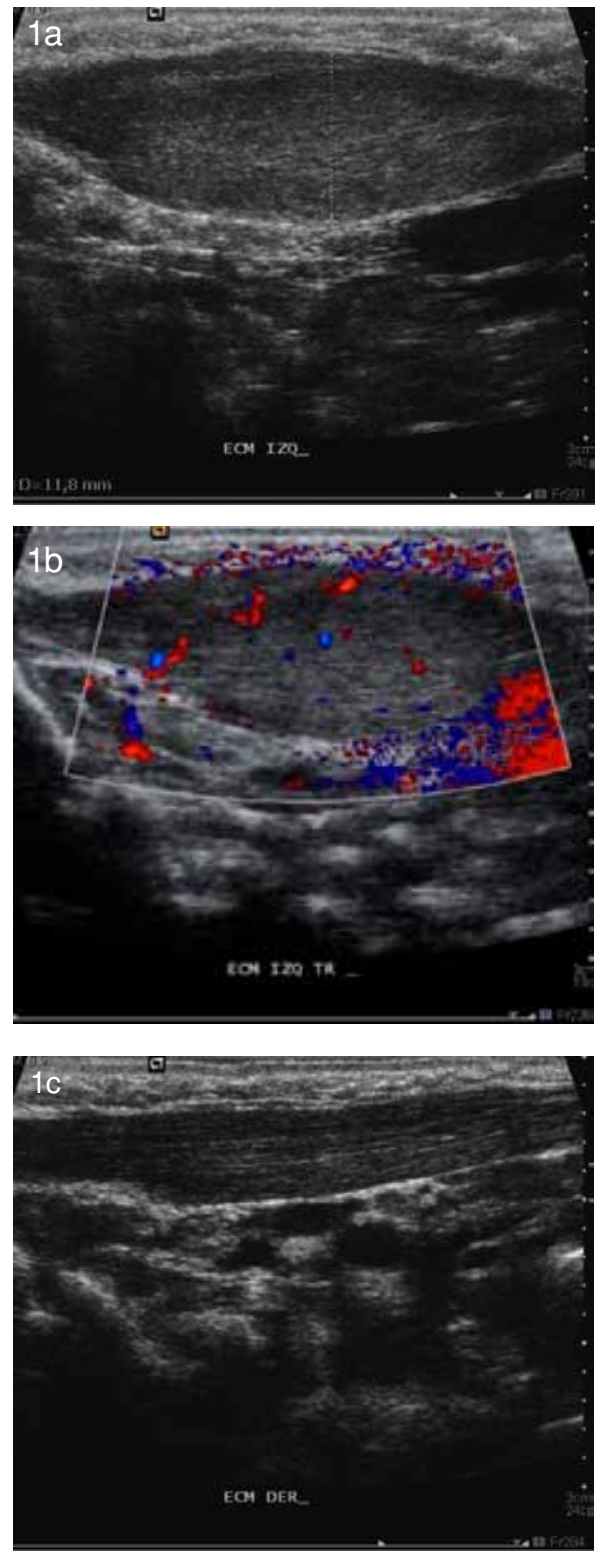

Figura 1. Paciente de 20 días, con franca inclinación de la cabeza hacia la derecha. Ultrasonido, imagen longitudinal del cuello, demuestra aumento de volumen (a) y vascularización (b) del músculo ECM izquierdo respecto del contralateral (c).

\section{Hematoma del músculo Esternocleidomastoideo}

La tortícolis congénita, previamente descrita, debe ser distinguida de otras afecciones infiltrativas menos frecuentes del ECM, como la fibrosis y los hematomas. La mayoría de los hematomas del ECM se dan en el período neonatal, y son secundarios a traumatismo obstétrico, donde el estiramiento del músculo genera una hemorragia en el interior de la vaina muscular, que suele resolverse en forma espontánea. La presentación más tardía suele darse en el contexto de traumatismos de moderada a alta energía (Figura 2).
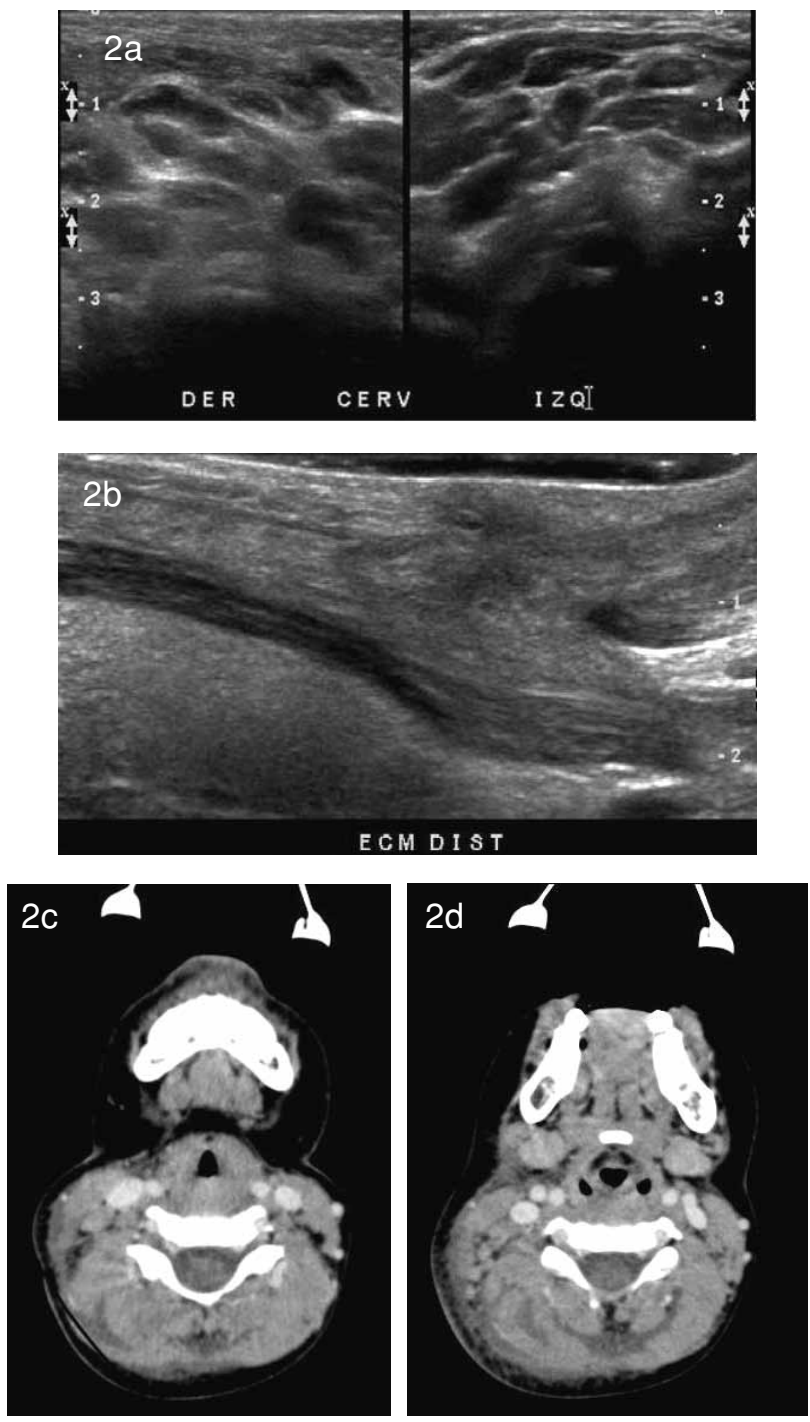

Figura 2. Paciente de 3 años, dolor y aumento de volumen cervical derecho tras una contusión directa de alta energía (accidente en bicicleta). Ultrasonido muestra pérdida de definición de los planos musculares y aumento de la ecogenicidad a derecha en imagen transversal comparativa (a) y longitudinal (b). TC demuestra aumento de la densidad del músculo (c) y de partes blandas vecinas (d).

\section{Fibrosis del músculo Esternocleidomastoideo}

Corresponde a una patología infrecuente y de etiología poco aclarada; el término muchas veces se emplea como sinónimo de tortícolis congénita, pero tanto su presentación clínica como imaginológica difieren. Se presenta en más allá del período neonatal, en pacientes con lateralización persistente de la cabeza y con frecuencia historia de múltiples tratamientos kinésicos, con escasa o nula mejoría (Figura 3). 

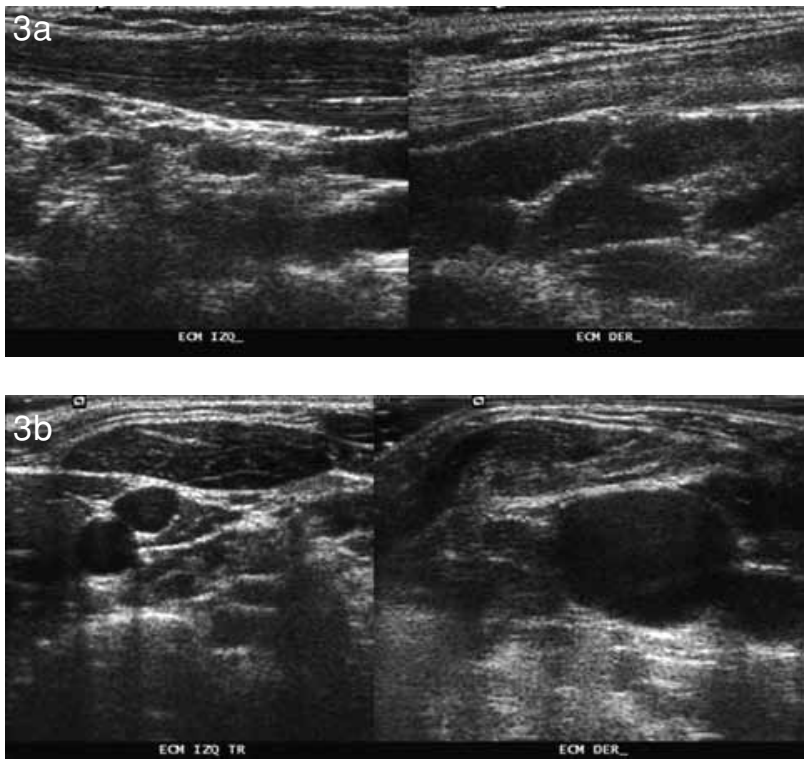

Figura 3. Niño de 7 años, con antecedente de tortícolis desde el nacimiento. US muestra disminución del espesory alteración de la ecoestructura del ECM derecho, adelgazado y ecogénico, en imágenes comparativas en plano axial (a) y longitudinal (b).

\section{Adenitis cervical}

El término "adenitis cervical" ha sido usado como sinónimo de la presencia de adenopatías. Estrictamente debiera reservarse para aquellos cuadros en que éstas se acompañan de cambios inflamatorios del tejido adyacente, para distinguirlo de la hiperplasia linfática reactiva que frecuentemente acompaña a las infecciones orofaciales en los niños. La adenitis cervical aguda está relacionada principalmente con infecciones bacterianas. Habitualmente son adenopatías de 2 a 3 centímetros, dolorosas a la palpación y unilaterales, en un cuadro habitualmente agudo de 5 o menos días de duración. Más del $80 \%$ de los casos se deben a Staphylococcus aureus y Streptococcus. pyogenes. Las infecciones por estas bacterias son más frecuente en preescolares, secundarias a un foco orofaríngeo o cutáneo. La complicación más frecuente es la abscedación, que aparece en el 10 a $25 \%$ de los casos. Las infecciones por anaerobios suelen aparecer en niños mayores con patología dentaria (Figura 4). La trombosis yugular, como parte del proceso séptico o Síndrome de Lemierre, es una complicación más rara. Se ha descrito con mayor frecuencia relacionada a procesos infecciosos faríngeos u odontógenos (Figura 5).

\section{Absceso retrofaríngeo}

Corresponde a la infección potencialmente letal del espacio retrofaríngeo, más frecuentemente de etiología infecciosa, en general, secundaria a la extensión de infecciones orofaríngeas a las estructuras linfáticas del retrofarinx, pudiendo ser también secundaria a
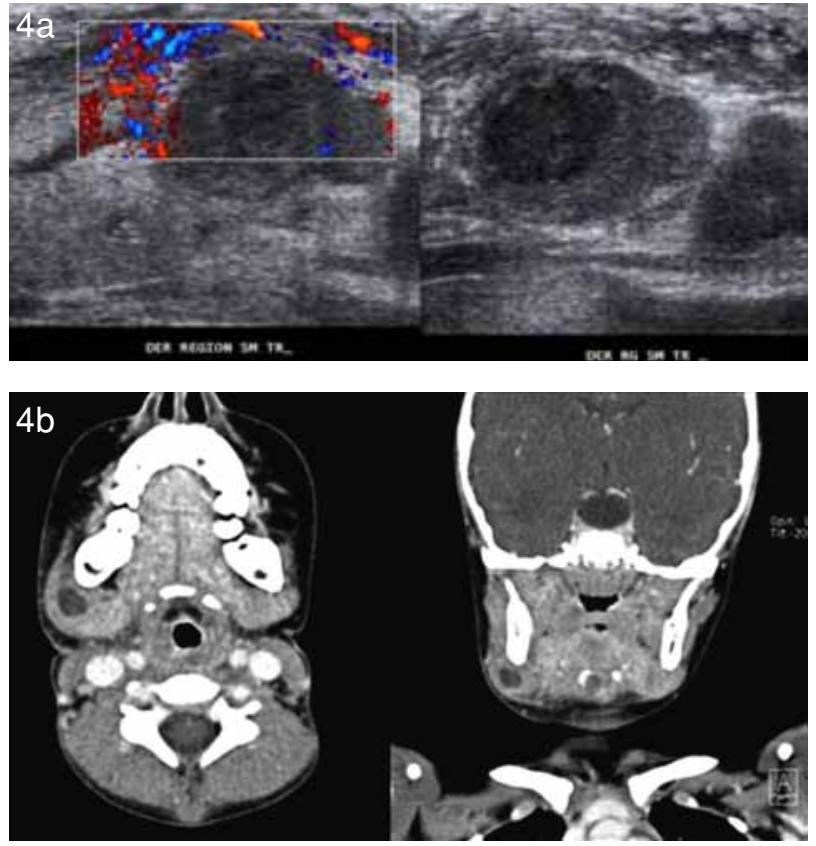

Figura 4. Paciente de 4 años, sin antecedentes mórbidos relevantes, aumento de volumen cervical derecho asociado a fiebre con lateralización cervical. US muestra extensos conglomerados adenopáticos submaxilares derechos, con colecciones anecogénicas sin flujo vascular y cambios inflamatorios del tejido adiposo adyacente (a). TC muestra adenopatía submaxilar derecha, con área de necrosis central (b).
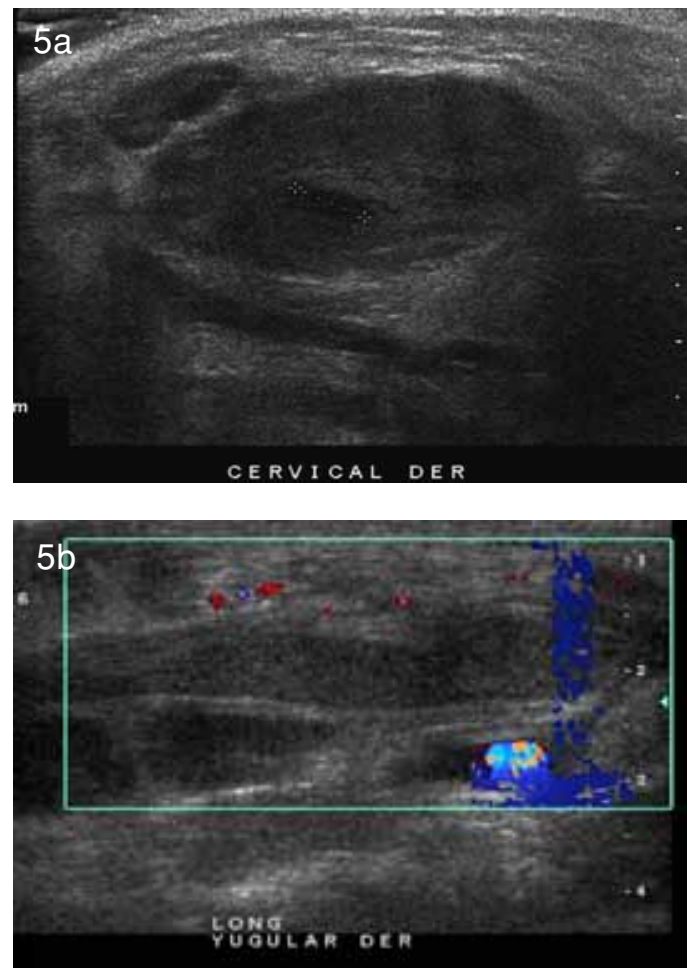

Figura 5. Síndrome de Lemierre. Paciente de 18 meses, con infección faríngea, adenoflegmón cervical y trombosis yugular. US muestra adenopatía con un área necrótica (a), aumento de calibre de la vena yugular interna derecha, con contenido hipoecogénico endoluminal y ausencia de flujo en imagen Doppler color (b). 
trauma, cuerpos extraños o iatrogenia. Hasta el 75\% de los casos se da en menores de 5 años, debido al aumento proporcional de tejido linfático en esta ubicación a estas edades, que posteriormente involuciona. La presentación clínica es variable, incluyendo disnea y estridor, salivación, síntomas meníngeos o franca sepsis. Los hallazgos imaginológicos en la radiografía simple son escasos, pudiendo incluir aumento de las partes blandas prevertebrales, siendo la rara presencia de búrbujas, el único signo patognomónico de absceso. La TC y RM demuestran aumento de volumen del espacio retrofaríngeo, asociado a la presencia de una colección que presenta impregnación anular con el uso de contraste, con desplazamiento asociado de la vía área y de los espacios parafaríngeos y carotídeos. El manejo es el drenaje quirúrgico de urgencia, por el alto riesgo de extensión al mediastino y su complicación con mediastinitis, frecuentemente fatal (Figura 6).

\section{Absceso tiroídeo}

El absceso tiroídeo es un cuadro infrecuente y una emergencia endocrina potencialmente fatal. Representa el 0,1 a 0,7\% de las patologías tiroídeas. La infección tiroídea puede resultar de una diseminación hematógena, linfática, o por contigüidad de una infección del cuello u orofaringe, por la presencia de algún cuerpo extraño o perforación esofágica. En niños, la infección de la tiroides rara vez se origina en la glándula misma, siendo lo más frecuente que existan alteraciones anatómicas que faciliten el paso de agentes infecciosos desde el tracto respiratorio a la glándula, siendo la más frecuente la fístula del seno piriforme. El cuadro clínico se caracteriza por disfagia, disfonía, dolor, fiebre y aumento de volumen de la zona; si el cuadro progresa, puede existir compromiso obstructivo de vía aérea y sepsis. La función tiroídea es normal en el $83 \%$ de los casos, existiendo reportes aislados de hipertiroidismo. La ecografía es el estudio de primera elección por su bajo costo e invasividad, demostrando un área hipoecogénica peritiroídea, compatible con un absceso. La TC y la RM son capaces de demostrar el compromiso tiroídeo y peritiroídeo, y eventualmente la presencia de una fístula, de forma directa o utilizando aire como medio de contraste. La TC es superior en demostrar la presencia de aire en el trayecto fistuloso y en delimitar el compromiso tiroídeo, por lo que esta técnica es preferida para la valoración de la extensión del proceso inflamatorio y sus complicaciones. La etiología es variada, siendo los Gram positivos los más frecuentes. En pacientes inmunosuprimidos, deben sospecharse agentes oportunistas, como Pneumocystis jirovecii y hongos. Una vez superado el proceso agudo, es perentorio
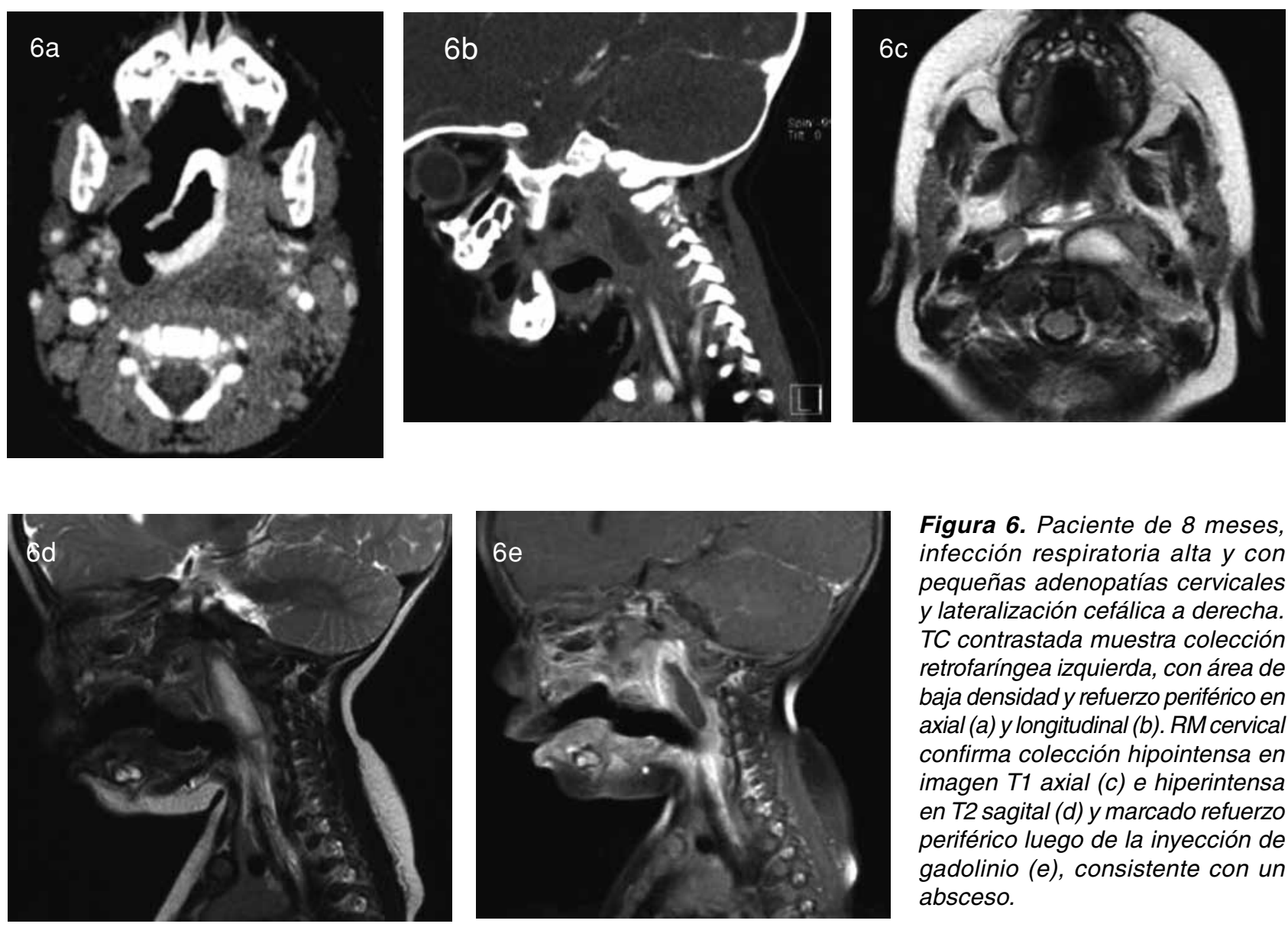

Figura 6. Paciente de 8 meses, infección respiratoria alta y con pequeñas adenopatías cervicales y lateralización cefálica a derecha. TC contrastada muestra colección retrofaríngea izquierda, con área de baja densidad y refuerzo periférico en axial (a) y longitudinal (b). RM cervical confirma colección hipointensa en imagen $T 1$ axial (c) e hiperintensa en T2 sagital (d) y marcado refuerzo periférico luego de la inyección de gadolinio (e), consistente con un absceso. 
descartar la presencia de una fístula del seno piriforme. Esta es una anomalía poco frecuente del desarrollo embrionario de la 3ra y 4ta bolsas faríngeas y cuyo origen exacto se desconoce. Se extiende desde el ápex de la faringe hacia la región peritiroídea, pudiendo terminar en el tiroides o adyacente a éste, lo que permite la infección bacteriana dentro o alrededor de la glándula. Dado que es una anomalía congénita, el desarrollo de un absceso tiroídeo secundario a una fístula del seno piriforme se presenta generalmente en niños. En más del $90 \%$ de los casos se presenta al lado izquierdo. El tratamiento consiste en antibioticoterapia de amplio espectro y drenaje quirúrgico en la fase aguda, con posterior fistulectomía en un segundo tiempo (Figura 7).

\section{B) Estructuras óseas de la base del cráneo y columna cervical}

\section{Plagiocefalia}

Es un trastorno caracterizado por una distorsión asimétrica del cráneo, por el aplanamiento uni o bilateral de la región occipital. Entre las fuerzas que pueden condicionar la deformidad craneal se incluyen diversos factores, tales como la posición in utero, apoyo continuo durante el sueño, escasa estimulación psicomotora, por ejemplo, que condicionan el apoyo posterior persistente del cráneo (plagiocefalia posicional), manteniendo abiertas las suturas posteriores a diferencia de los casos de plagiocefalia sinostótica. Un porcentaje alto de estos pacientes sufre de tortícolis congénita, pudiendo asimismo desarrollarse una posición viciosa de la cabeza en forma secundaria al aplanamiento craneano. Cuando existen dudas en el diagnóstico, debe realizarse una radiografía simple de cráneo para visualizar la permeabilidad de las suturas parietooccipitales, y descartar así las raras formas asociadas a craneosinostosis. La técnica de elección es la TC craneal con reconstrucción 3D, que permite caracterizar y cuantificar el grado de plagiocefalia a través del uso de índices de asimetría, además de permitir observar un ligero agrandamiento del espacio subaracnoideo, hallazgo asociado hasta en un $25 \%$ de los casos (Figura 8).

\section{Anomalía de Sprengel}

Las anomalías músculoesqueléticas de la cintura escapular también pueden asociarse a alteraciones de la alineación cervical debido al desbalance dinámico entre las fuerzas, incluyendo en este grupo fundamentalmente aquellas causas de compromiso muscular asimétrico de los músculos pectoral y serrato anterior. La anomalía de Sprengel o escápula congénita no descendida corresponde a una de las causas del hallazgo clínico de «escápula alada». Esta anomalía ocurre debido al fallo en el descenso normal de ésta hacia la pared torácica entre las semanas 9-12, y se manifiesta por un polo inferior aducido y un polo superior elevado, que puede estar incluso a nivel de las vértebras cervicales altas. Todos estos factores contribuyen a la significativa limitación de la movilidad escapulotorácia que presentan estos pacientes y que puede asociarse a otras alteraciones esqueléticas. El llamado "hueso omovertebral" es
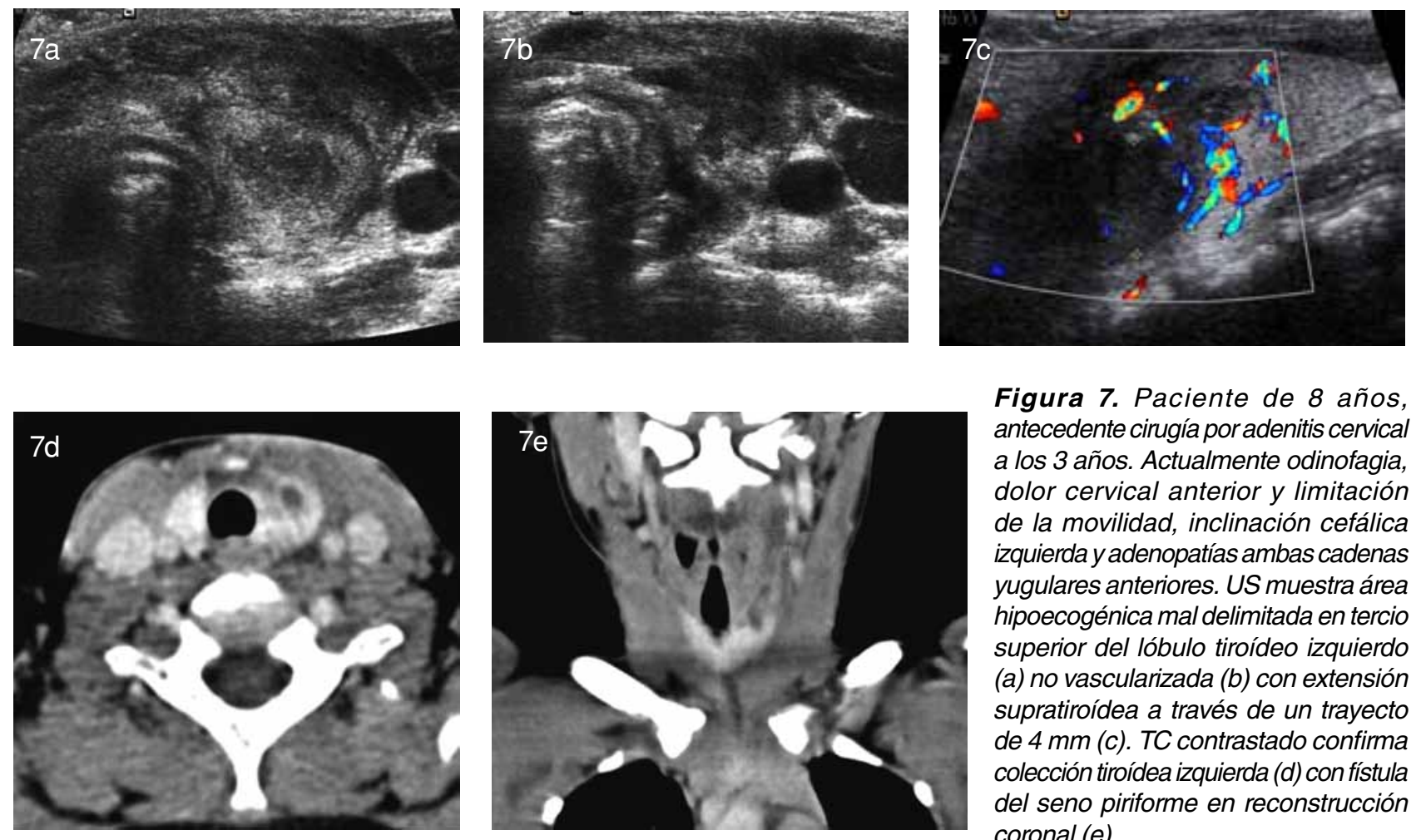

Figura 7. Paciente de 8 años, antecedente cirugía por adenitis cervical a los 3 años. Actualmente odinofagia, dolor cervical anterior y limitación de la movilidad, inclinación cefálica izquierda y adenopatías ambas cadenas yugulares anteriores. US muestra área hipoecogénica mal delimitada en tercio superior del lóbulo tiroídeo izquierdo (a) no vascularizada (b) con extensión supratiroídea a través de un trayecto de $4 \mathrm{~mm}$ (c). TC contrastado confirma colección tiroídea izquierda (d) con fístula del seno piriforme en reconstrucción coronal (e). 
visible en aproximadamente un tercio de los casos de anomalía de Sprengel, y se extiende entre el borde medial de la escápula hasta los procesos espinosos de las vértebras cervicales C5 a C7 (Figuras 9 y 10).
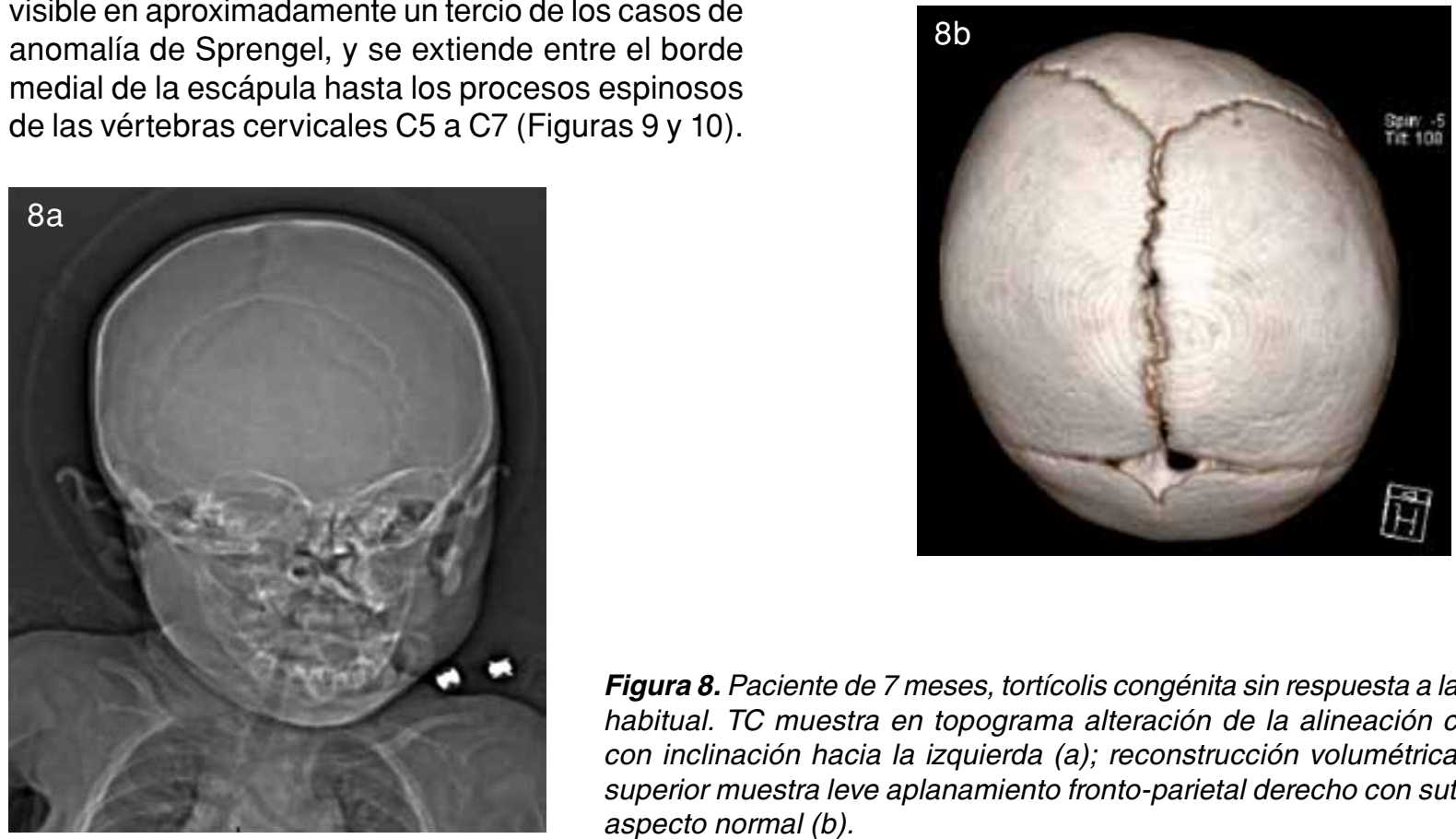

Figura 8. Paciente de 7 meses, tortícolis congénita sin respuesta a la terapia habitual. TC muestra en topograma alteración de la alineación cefálica, con inclinación hacia la izquierda (a); reconstrucción volumétrica, visión superior muestra leve aplanamiento fronto-parietal derecho con suturas de aspecto normal (b).

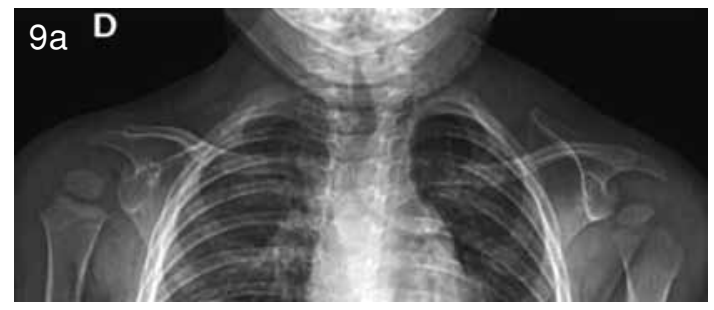

Figura 9. Paciente de 10 meses, inclinación cervical a derecha y limitación funcional del brazo y hombro izquierdos. Radiografía simple muestra escápula una escápula izquierda de menor tamaño, ascendida y rotada (a), mejor demostrada en TC reconstrucción volumétrica (b).
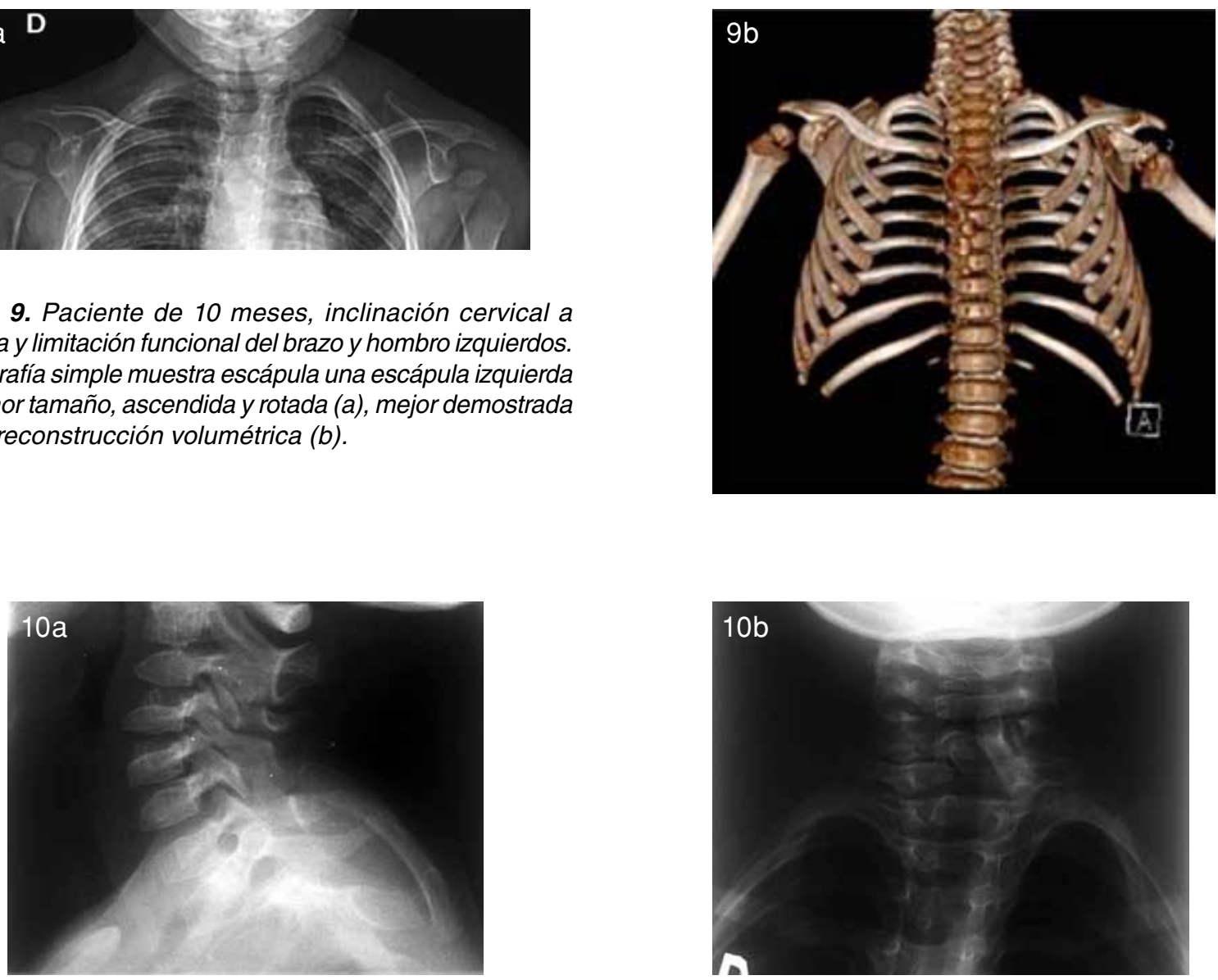

Figura 10. Paciente de 5 años portador de síndrome de Klippel-Feil con anomalía de Sprengel. Hueso omovertebral en radiografía de columna cervical lateral (a) y frontal (b) con fusión de elementos posteriores 


\section{Histiocitosis de células de Langerhans}

Corresponde a un desorden raro caracterizado por la proliferación y acumulación de histiocitos y eosinófilos en diversos tejidos, que comprende varias entidades clínicas distintas, entre las cuales la más frecuente corresponde al llamado granuloma eosinófilo, (forma beniga que comprende compromiso óseo monostótico aislado). Esta condición, de etiopatogenia no bien aclarada, puede darse a cualquier edad pero presenta un claro predominio en la edad pediátrica. En el granuloma eosinófilo cualquier hueso puede estar comprometido, pero existe una predilección por los huesos planos, entre los cuales el cráneo es el más frecuentemente afectado, tanto la calota como la base del cráneo. La clínica dependerá del hueso comprometido, variando desde dolor local y aumento de volumen hasta síntomas neurológicos (ej., cuando existe compromiso del proceso petroso del temporal). Los hallazgos son variables según la fase de la enfermedad, con lesiones osteolíticas de aspecto agresivo en la fase aguda (reacción perióstica maligna, masa de partes blandas, etc.), que van adquiriendo un aspecto más benigno hacia las fases intermedia y crónica de la enfermedad (borde esclerótico, reacción perióstica unilamelar, etc). En el cráneo las lesiones afectan las tablas externa e interna con un compromiso característicamente desigual, y carecen de reacción perióstica significativa. Otros hallazos incluyen la presencia de un secuestro óseo, que debe distinguirse fundamentalmente de la infección en la edad pediátrica. La TC está indicada para caracterizar el compromiso óseo, y la RM para delimitar mejor la eventual extensión a las partes blandas intra y extracraneanas adyacentes (Figura 11).

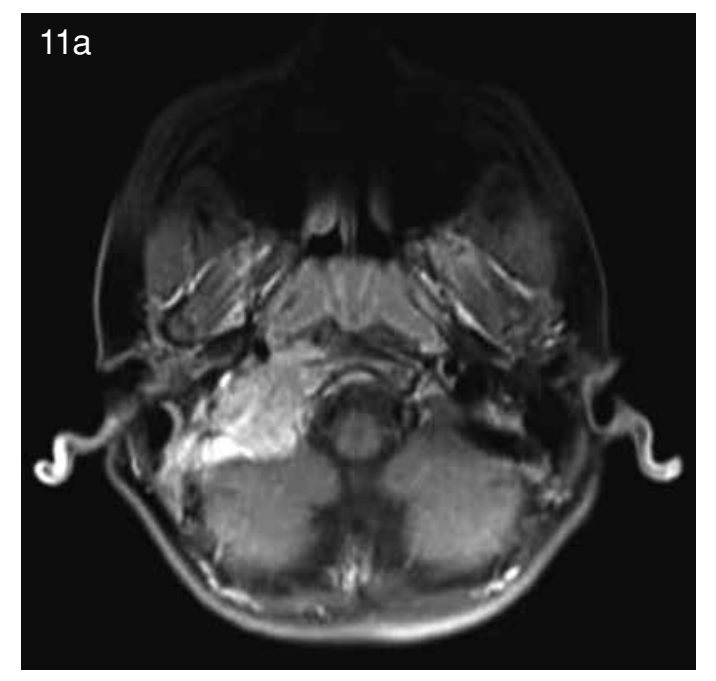

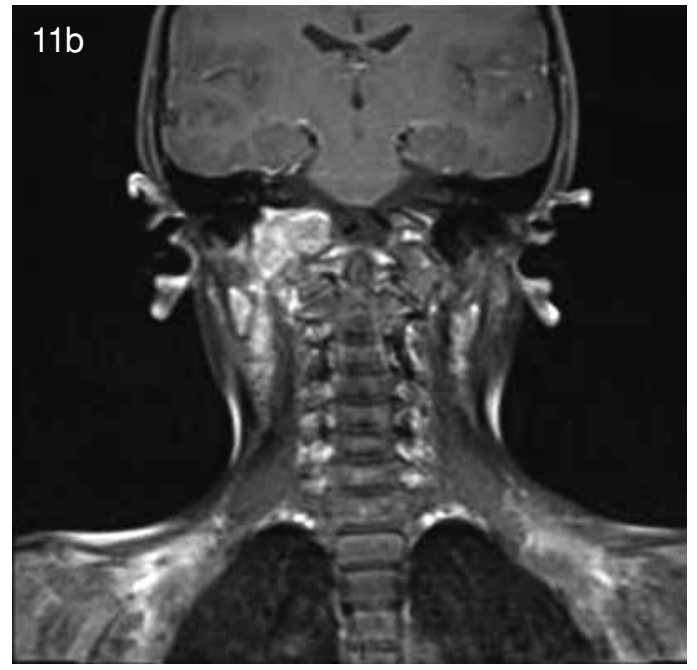
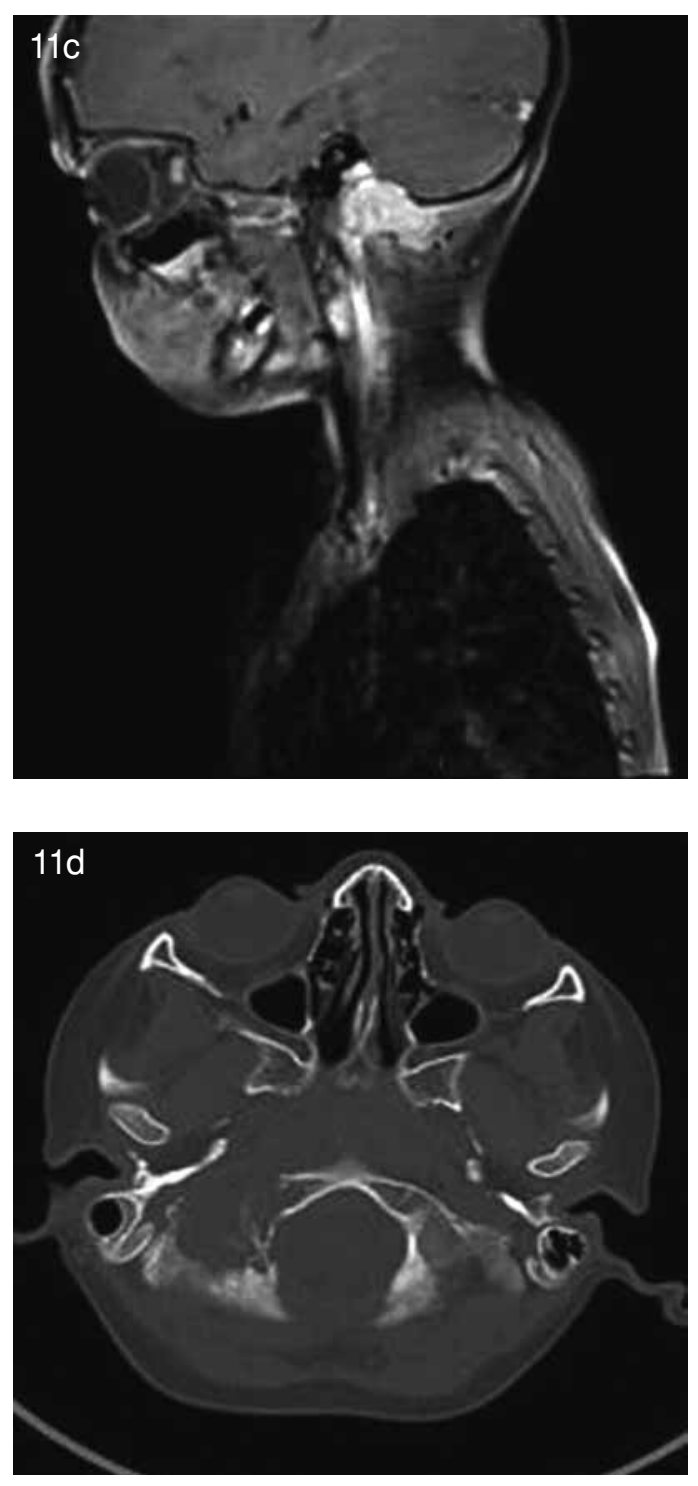

Figura 11. Paciente de 6 años, cervicalgia no traumática asociada a tortícolis y limitación de la rotación derecha. RM cervical T1 con gadolinio, en axial (a), coronal (b) y sagital (c) muestra masa del cóndilo occipital derecho, con extensión parcial hacia el cuello y significativo realce homogéneo. TC muestra lesión osteolítica y expansiva del cóndilo en imagen sagital con compromiso parcial del foramen yugular (d). Biopsia positiva para histiocitosis de células de Langerhans Grupo 3. 


\section{Subluxación rotatoria atlanto-axoidea}

Si bien la luxación rotatoria atlanto-axoidea se ha descrito en todas las edades, es una patología casi exclusiva de los niños. Se produce por un mecanismo de flexión y rotación de la columna cervical asociado a debilidad del ligamento transverso, secundario frecuentemente a traumas banales como ejercicios gimnásticos menores aunque también puede verse en traumatismos severos. Se describe además en el transcurso de infecciones respiratorias altas (Síndrome de Grisel) o en el post operatorio de amigdalectomías. Clínicamente, la cabeza se encuentra rotada hacia un lado con el cuello en la dirección opuesta. La rotación
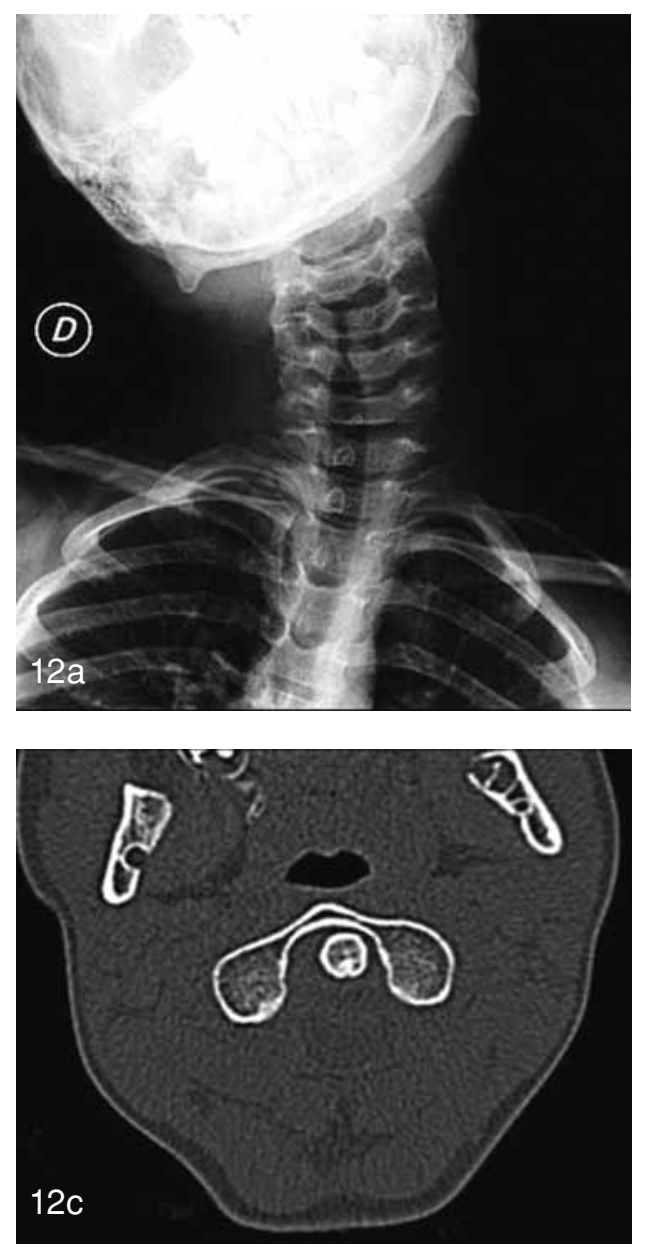

de la cabeza hacia el lado contrario está limitada y se acompaña de intenso espasmo del músculo ECM, siendo imposible restablecer la posición normal en forma voluntaria o forzada. A esta altura, el canal medular es amplio por lo que en general esta alteración no se asocia a signos neurológicos. En radiografía simple puede observarse desalineación de las masas laterales del atlas, una de las cuales queda situada por delante del odontoides, hallazgo que se representa mejor en TC. El tratamiento es conservador, consistente en manejo del dolor y tracción cervical con jáquima. La reducción quirúrgica es rara, aunque se describe para luxaciones persistentes o recidivantes (Figura 12).
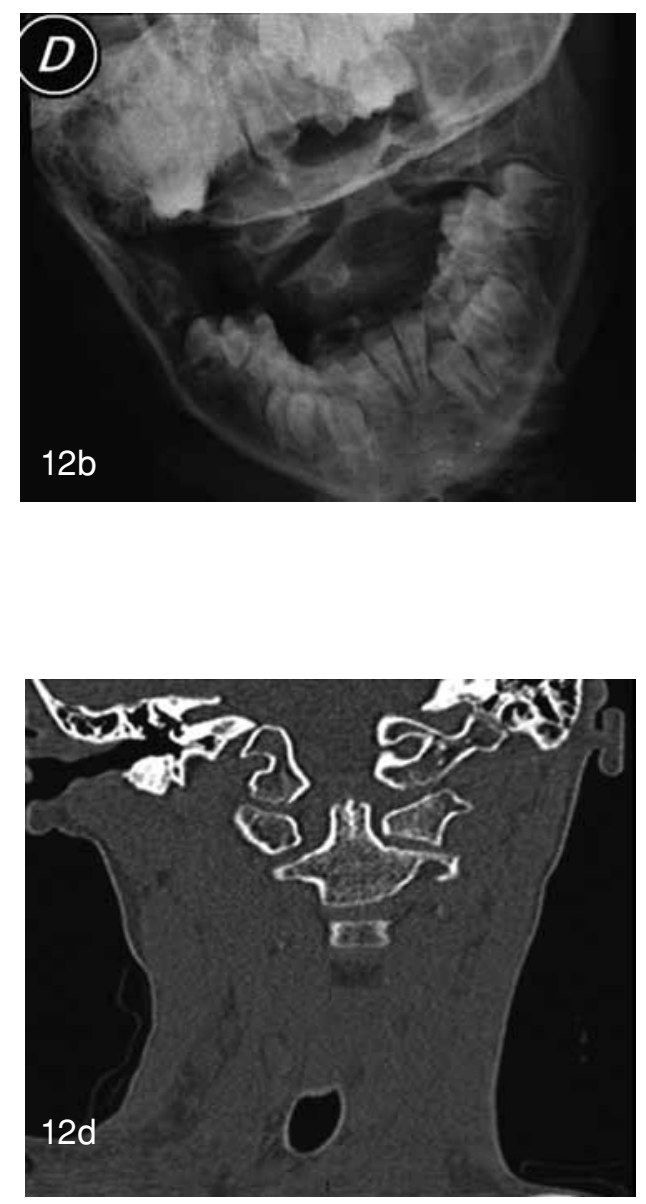

Figura 12. Paciente de 10 años, accidente de tránsito. Cervicalgia, limitación funcional e inclinación de la cabeza hacia el lado izquierdo. Radiografía de columna cervical, muestra marcada inclinación cervical a derecha en proyección frontal (a) con asimetría entre las masas laterales del atlas respecto del odontoides en proyección transoral (b). TC muestra subluxación rotatoria asimetría, inclinación y rotación de las masas laterales de C1 respecto de C2, en reconstrucción axial (c) y coronal (d).

\section{Escoliosis congénita}

Se define escoliosis como la presencia de una o más curvas laterales de la columna vertebral en el plano coronal. Usualmente se clasifica en primaria o idiopática y secundaria, las que a su vez se clasifican de acuerdo a su causa. Entre las causas de escoliosis pueden considerarse las enfermedades neuromus- culares, alteraciones congénitas y del desarrollo y algunos tumores. En términos generales la escoliosis idiopática es el tipo más común (80\%) seguida por la escoliosis congénita $(10 \%)^{(14)}$. La radiografía simple y la TC son los métodos de elección para documentar las alteraciones óseas y la RM está indicada cuando se sospecha una alteración neuropática (Figura 13). 

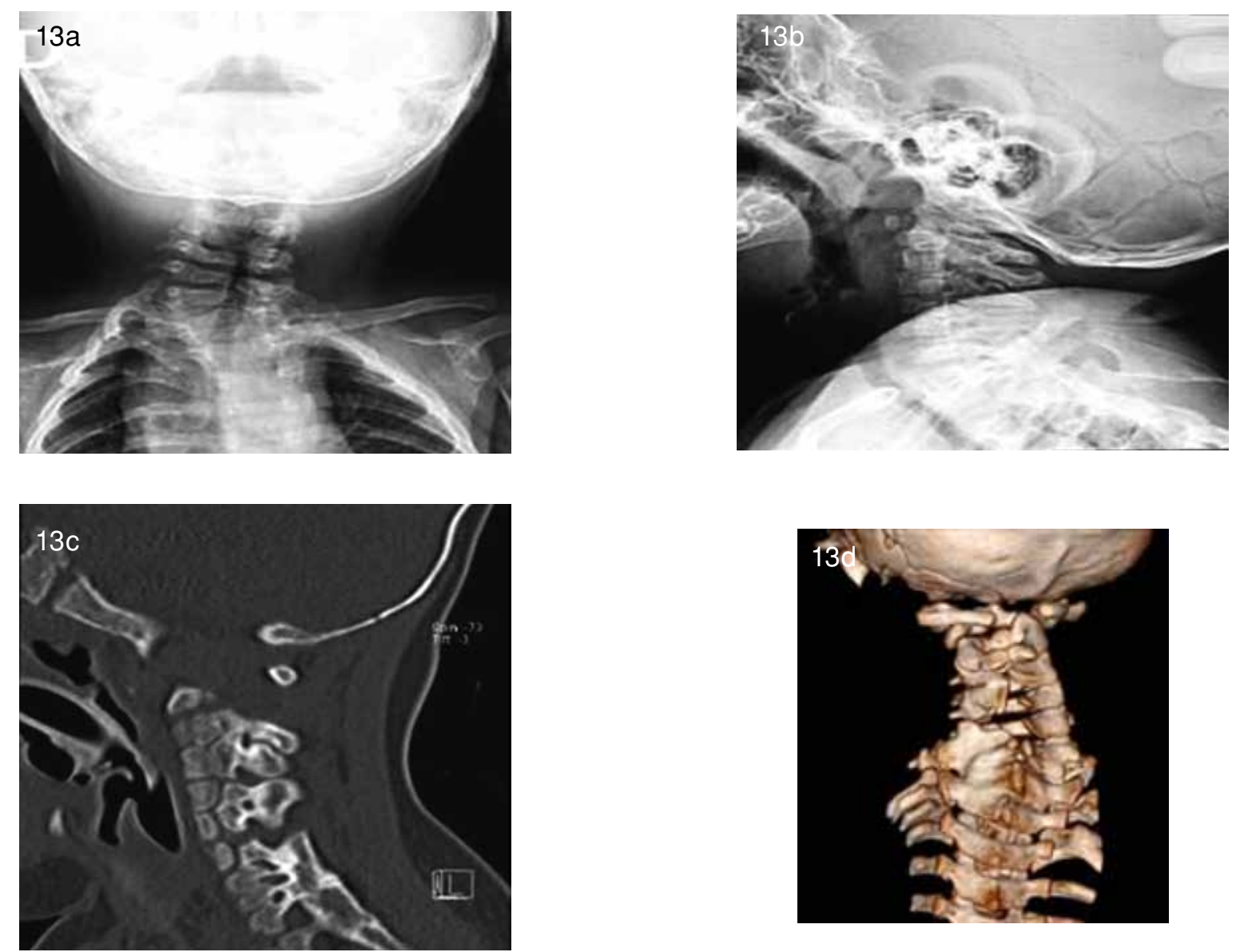

Figura 13. Paciente de 7 meses, tortícolis sin respuesta a tratamiento kinésico. Radiografía simple proyecciones frontal (a) y lateral (b) muestran malformaciones vertebrales consistentes en bloques y hemivértebras, mejor demostradas en TC con falta de formación de los arcos anterior y posterior de C1 en reconstrucciones sagital (c) y volumétrica (d).

\section{Conclusión}

El espectro de causas de tortícolis en la edad pediátrica es muy amplio y las imágenes pueden ser de gran utilidad para el clínico para lograr un diagnóstico acertado y precoz.

\section{Bibliografía}

1. Vial I, García C, Accorsi O, Zúñiga R. Tortícolis muscular congénita: Hallazgos ultrasonográficos. Rev Chil Pediatr 1995; 66(3): 156-161.

2. Caffey J. Caffey's Pediatric Diagnostic Imaging. Salvat, $10^{\circ}$ edition. pp. 345-351.

3. Laguia M, Lahoz T, Martinez J, Valero J, Fraile J, Cámara F. Síndrome de Lemierre: tromboflebitis séptica de la yugular interna secundaria a amigdalitis aguda. Acta Otorrinolaringol Esp 2001; 52: 163-166.

4. Amin S, Sajad A, Rashid W. Acute retropharyngeal abscess with torticollis and cervical subluxation. A case report and review of literature. Int. J Pediatr Otorhinolaryngol Extra 2011; 6(4): 252-255.

5. Craig F, Schunk J. Retropharyngeal Abscess in Children: Clinical Presentation, Utility of Imaging, and Current Management. Pediatrics 2003; 111: 1394-1398.

6. Grob F. Absceso Tiroídeo con Fístula del Seno Piriforme. Tres Casos Clínicos. Rev Chil Pediatr 2011; 82(1): 49-55.
7. Fernandez M, Gozálvez J, Hernández E, Ruiz Cano $R$. Tiroiditis agudas y abscesos cervicales como manifestaciones de las fístulas del seno piriforme. Cir Pediatr 2009; 22: 157-116.

8. Serramito R, Gelabert G. Publicación mensual para formación continua en neurocirugía. Neurocirugía Contemporánea. Plagiocefalia posicional 2008; 2(7): 1-5.

9. Boon J, Potgieter D, Van Jaarsveld Z, Frantzen DJ. Congenital Undescended Scapula (Sprengel Deformity): A Case Study. Clinical Anatomy 2002; 15: 139-142.

10. Azouz M. CT demonstration of omovertebral bone. Pediatr Radiol 2007; 37: 404.

11. Azouz M. Langerhans' cell histiocytosis: pathology, imaging and treatment of skeletal involvement. Pediatr Radiol 2005; 35: 103-115.

12. Ortega $X$, Linderman $C$, Gálvez M, Chain A. Dolor cervical: Caso clínico para diagnóstico. Rev Chil Radiol 2007; 13(1): 49-50.

13. González O, Cardoso A, Rosales M. Subluxación rotatoria atlanto-axial en un paciente pediátrico, reporte de caso. Revista Mexicana de Ortopedia Pediátrica 2008; 10(1): 41-48.

14. Kim H, Kim HS, Moon E, Yoon C, Chung T, Song H, et al. Scoliosis Imaging: What radiologist should know. Radiographics 2010; 30: 1823-1842. 